\title{
Métodos microbiológicos para mitigar problemas de contaminación generados por la industria de la celulosa y el papel
}

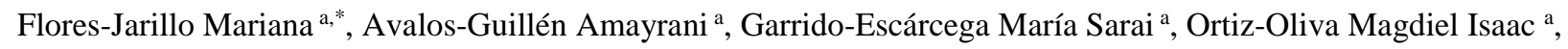 \\ Saldaña-Ramírez Diego ${ }^{\text {a }}$ \\ a Área Académica de Química. Universidad Autónoma del Estado de Hidalgo. Carr. Pachuca Tulancingo Km 4.5, Mineral de la Reforma, Hidalgo 42184, México.
}

\section{Resumen}

Aunque se cree que el papel es un material sustentable, el proceso para su obtención implica un gran consumo de agua y electricidad además de la generación de muchos contaminantes. La idea de la sustentabilidad de este material recae en que puede ser reciclado, sin embargo, a nivel mundial sólo se recicla el 55\% de la producción total. Existen algunas opciones biotecnológicas que podrían ayudar a mitigar los problemas de contaminación que genera esta industria como la producción de celulosa a través de bacterias, la extracción de celulosa a partir de material maderable a través de enzimas y el tratamiento de los efluentes a partir de microorganismos. Aunque estas opciones no constituyen una solución total al problema, sí pueden ser parte de la solución al mismo.

Palabras Clave: biocelulosa, biopulpeo, efluentes, colorantes, bioetanol 2G.

\section{Introducción}

El papel ha sido importante en la transmisión de conocimientos, costumbres y la historia de la humanidad. En la actualidad, el papel tiene diversos usos: embalaje (cartón), impresión y escritura (papel bond) y limpieza (papel tisú, o tissue por su nombre en inglés); su uso es tan amplio que en 2015 se utilizaron 406 millones de toneladas a nivel mundial (FAO, 2015). El papel está constituido principalmente por fibras vegetales, específicamente de celulosa la cual es un biopolímero lineal que forma parte de la pared celular de las plantas y está formado por unidades de glucosa unidas entre sí por medio de enlaces glucosídicos $\beta$ (1-4) (Figura 1) (Wertz et al., 2010). A nivel industrial las principales fuentes de celulosa son árboles de madera dura, como eucalipto y álamo, y de madera blanda, como pino y abeto, por lo que existe un alto impacto ambiental por tala forestal. Además, durante la elaboración del papel existe un alto consumo de agua y de energía y ocurre la descarga de gran cantidad de contaminantes al ambiente.

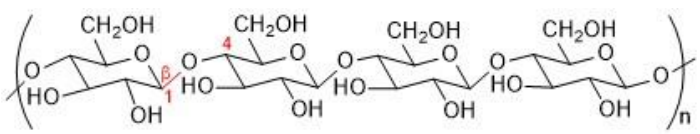

Figura 1: Estructura química de la celulosa.

La característica principal por la que el papel se considera un material ecológico o sustentable es su capacidad para ser reciclado. Sin embargo, esta ventaja puede perderse en países, como México dónde no es obligatorio separar la basura desde las fuentes primarias, sino que, en el mejor de los casos, debe ser separada y clasificada después de su primera disposición mezclada con otros desechos. En contraste con la producción total, sólo 225 millones de toneladas de papel, aproximadamente la mitad, son recuperadas para su reciclaje a nivel mundial (FAO, 2015). En consecuencia, se han buscado diversas alternativas para obtener celulosa disminuyendo las afectaciones ambientales, por ejemplo, la obtención de celulosa vegetal a partir de fibras alternativas como de bagazo de caña o a partir de cultivos maderables controlados donde los árboles son cortados y repuestos a cierta edad. Sin embargo, esta técnica se ha criticado porque provoca agotamiento de los suelos. También se han explorado opciones que incluyen la obtención de celulosa a partir de derivados bencilados de glucosa por síntesis química y a partir de hongos y bacterias por síntesis enzimática (ChávezPacheco et al., 2004).

\section{Celulosa Bacteriana}

La celulosa bacteriana, también llamada celulosa microbacteriana o biocelulosa, es producida por diferentes géneros de bacterias del reino monera, como Achromobacter, Aerobacter, Azotobacter, Agrobacterium, Rhizobium, Sarcina, Zoogloea, Salmonella y Gluconacetobacter y tiene una estructura semejante a la de la celulosa vegetal (Chawla et al., 2009).

La cepa que tiene mayor capacidad de producción dentro de las especies estudiadas es Gluconacetobacter xylinum. Esta bacteria aerobia Gram-negativa realiza la oxidación

\footnotetext{
* Autor en correspondencia.

Correo electrónico: mariana_flores@uaeh.edu.mx (Mariana Flores)
} 
incompleta de fuentes de carbono como glucosa, sacarosa, manitol o arabinol y puede aislarse de frutas y vegetales en proceso de descomposición (Garcia-Sanchez et al., 2016). La bacteria convierte estas fuentes de carbono en uridindifosfato glucosa (UDPG, por sus siglas en inglés) que al polimerizarse y asociarse entre sí forman cintas que constituyen las fibras de celulosa (Wertz et al., 2010).

Aunque la disparidad de los volúmenes de producción no permite una comparación directa entre la celulosa bacteriana (gramos) y la celulosa de fuentes vegetales (toneladas), la eficiencia de producción bacteriana llega a 15\% de rendimiento en g/L (Chawla et al., 2009) en comparación con los rendimientos de $38-50 \%$ que se obtienen a partir de la madera.

La producción de celulosa bacteriana depende de la concentración de la fuente de carbono, del pH (4-6) y la temperatura $\left(28-30{ }^{\circ} \mathrm{C}\right)$. La macroestructura de las fibras de celulosa bacteriana es determinada por las condiciones de cultivo. En cultivo estático se obtienen películas de celulosa a partir de 24 a 72 horas y en cultivo agitado se obtienen granos (pellets) en tiempos de 1 a dos semanas (Chávez- Pacheco et al., 2004). La celulosa bacteriana destaca por su pureza, grado de cristalinidad, resistencia a la presión, elasticidad, durabilidad, así como su mayor retención de agua con respecto a la celulosa vegetal y es inerte a nivel metabólico por lo que se usa en la ingeniería de tejidos como sustituto temporal para tratar heridas y elaboración de papel de alta calidad en la restauración de documentos.

\section{Purificación de celulosa a partir de madera}

Para obtener celulosa pura a partir de la madera es necesario separarla de otros componentes como la hemicelulosa, que es un heteropolímero de glucosa y otros azúcares, y la lignina, que es un polímero fenólico con estructura altamente amorfa (Figura 2).

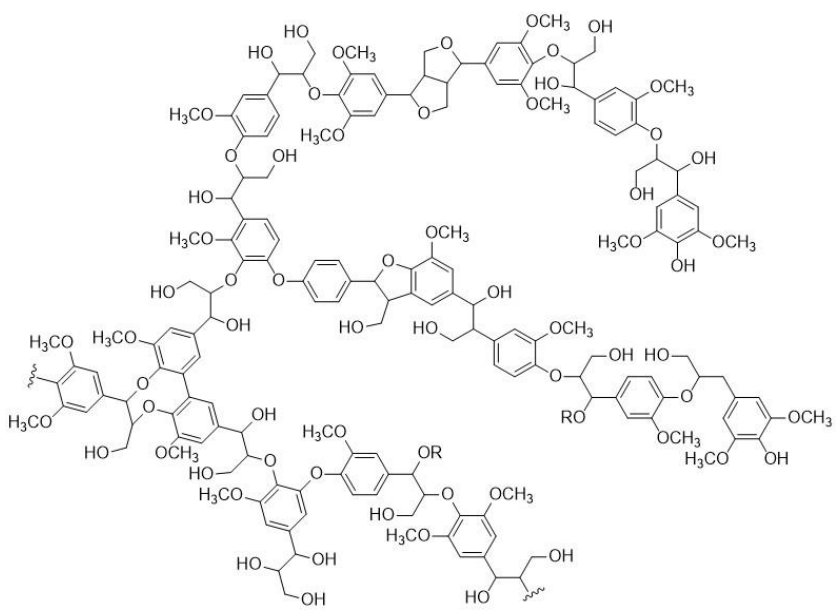

Figura 2: Estructura química de la lignina.

A menor proporción de lignina que contenga un papel será de mayor calidad: será más blanco, más resistente y tendrá menor tendencia a adquirir color amarillo con el paso del tiempo. Para separar el grueso de la lignina se usa principalmente el método Kraft: las astillas de madera se tratan con hidróxido de sodio y sulfuro de sodio a presión y temperatura alta. Además del gasto energético, este proceso genera óxidos de azufre (SOx) causantes de lluvia ácida, y vapores de ácido sulfhídrico, metil mercaptano, sulfuro de dimetilo y disulfuro de dimetilo que causan mal olor, náuseas e irritación de piel y garganta. Posteriormente, se realiza una etapa de blanqueo que elimina la lignina residual mediante el uso de cloro molecular u óxido de cloro, en consecuencia, se generan compuestos organoclorados potencialmente genotóxicos. Alternativamente se pueden seguir tratamientos menos contaminantes con oxígeno, peróxidos y/o ozono. Una vez separada, la lignina o los productos de su despolimerización, pasan al efluente del proceso donde se condensan y queman en calderas para producir electricidad, pero también gases de efecto invernadero.

La lignina es difícil de biodegradar debido a su estructura compleja. Sin embargo, el estudio de hongos de la pudrición blanca ha hecho posible proponer el uso de enzimas en el proceso de pulpeo y blanqueo de celulosa (Arias-Orozco et al., 2012). Estos hongos basidiomicetos son capaces de invadir los tejidos vegetales a través del lumen del sistema vascular de la planta al secretar enzimas capaces de realizar la degradación de lignina y otros componentes de la madera. El uso de estas enzimas eliminaría o reduciría el uso de productos químicos y evitaría la emisión de productos secundarios potencialmente peligrosos. Entre las enzimas que se han estudiado se encuentran las xilanasas, que degradan hemicelulosa debilitando la estructura de la madera y haciéndola más susceptible al ataque por químicos, y las oxidasas degradadoras de lignina (peroxidasas y lacasas) que actúan rompiendo los enlaces de esta molécula recalcitrante. Aunque la acción de estas enzimas es degradar la lignina por medio de la producción de intermediarios reactivos llamados radicales libres existen diferencias de selectividad. Las peroxidasas son selectivas a compuestos aromáticos no fenólicos y actúan oxidando el anillo aromático y dan lugar a rupturas en los enlaces carbono-carbono de la lignina (Sánchez, 2006). Por su parte, las lacasas facilitan la oxidación de los compuestos fenólicos y aminas aromáticas que terminan efectuando la ruptura de la lignina. Para que las lacasas sean más efectivas en la degradación de compuestos aromáticos se ha explorado el uso de mediadores, que son compuestos capaces de iniciar una reacción por radicales libres. Para que el proceso siga siendo amigable con el medio ambiente, se han utilizado mediadores que provienen del mismo proceso Kraft como el siringaldehido o compuestos naturales como la vainillina (Cañas y Camareno, 2010).

Entre las especies de hongos que producen estas enzimas se encuentran Aspergilius Niger, Phanerochaete Chysosporium, Panus Tigrinus, Phlebia Radiata, Trametes Versicolor, Pycnoporus Cinnabarinus, Pleurotus Pulmonarius, Pleurotus Eryngii y en general toda la familia Pleurotus (Sánchez, 2006). Aunque los hongos han sido los microorganismos más estudiados, también se sabe que algunas cepas bacterianas e incluso algas tienen las enzimas para degradar moléculas del tipo de la lignina.

Aunque probablemente sea complicado separar el grueso de la lignina de la madera para obtener celulosa pura a partir de métodos puramente biotecnológicos, es posible que estos sirvan para eliminar la lignina residual, lo que eliminaría los químicos del proceso de blanqueo.

\section{Tratamiento de efluentes}


La mayoría de los contaminantes que se generan durante la obtención de pulpa de celulosa y fabricación de papel terminan en los efluentes de estas industrias. Aunque la tendencia es disminuir la cantidad de efluentes, en 2009 se estimaba que por cada tonelada de papel se generaban $150 \mathrm{~m}^{3}$ de efluentes (Singhal y Thakur, 2009). Entre los contaminantes que contienen dichos efluentes se pueden incluir compuestos orgánicos como hemicelulosa y otros azúcares, compuestos derivados de la despolimerización de lignina como taninos y fenoles, resinas, ácidos grasos, colorantes, abrillantadores ópticos y compuestos halogenados como las dioxinas (Ali y Sreekrishnan, 2001). El contenido de materia orgánica puede ser medido por medio de la demanda química de oxígeno (DQO) y la demanda biológica de oxígeno (DBO) que miden la cantidad de oxigeno necesaria para oxidar la materia orgánica por medios químicos o biológicos hasta convertirla en $\mathrm{CO}_{2}$ y agua. Un valor más alto de $\mathrm{DBO}$ o DQO significan mayor cantidad de materia orgánica y por tanto mayor contaminación. En los efluentes también se incluyen compuestos inorgánicos como agentes de encolado, rellenos y otros compuestos que se utilizan para lograr características específicas en el papel.

Ante este desafío se han desarrollado tratamientos físicoquímicos y biológicos, así como su combinación en serie. Algunos de los tratamientos físicoquímicos son la electrocoagulación, la ósmosis inversa, sistemas fotocatalíticos que actúan bajo irradiación UV y uso de ozono. Los métodos de tratamiento biológico implican el uso de bacterias (Pseudomonas, Bacillus, etc.), hongos (Trametes versicolor, Aspergillus niger, Trichoderma sp, etc.) algas (Microcystis, Chlorella, etc.) y enzimas. (Ali y Sreekrishnan, 2001).

Los sistemas de tratamiento de aguas residuales han utilizado poblaciones de bacterias, debido a que estas pueden aglomerarse en floculos produciendo una mejor sedimentación lo que provoca que el efluente termine más transparente y con mejor calidad (Vilaseca, 2001). Se han utilizado organismos aerobios, anaerobios o facultativos (que se pueden desarrollar en presencia o ausencia de oxígeno). Sin embargo, la digestión anaerobia tiene ventajas como la producción de energía en forma de metano, menor requerimiento de espacio al usar reactores más pequeños y una menor producción de lodos (Singh y Thakur, 2006).

El tratamiento biológico con cepas de hongos se debe a que el efluente contiene gran cantidad de compuestos aromáticos provenientes de la lignina. Las enzimas lacasas en los hongos han podido reducir la demanda química de oxígeno, así como el color causado por la lignina. Algunos estudios muestran que es posible mezclar tratamientos secuenciales con diferentes clases de microorganismos, por ejemplo, hongos y bacterias El tratamiento de efluentes con microorganismos puede implicar mecanismos de biosorción-fluculación y acción enzimática para obtener moléculas menos tóxicas.

\section{Degradación de colorantes azo}

La industria del papel utiliza los colorantes azo debido a su bajo costo, facilidad de preparación y a la variedad y estabilidad de los colores que pueden obtenerse. En estos colorantes el grupo funcional azo $(-\mathrm{N}=\mathrm{N}-)$ se encuentra enlazado a sistemas de anillos aromáticos conjugados (Ar$\mathrm{N}=\mathrm{N}-\mathrm{Ar}$ ). Estas moléculas generan efectos tóxicos en la flora y fauna del ecosistema y reducen la penetración de la luz, lo que disminuye la actividad fotosintética y la concentración de oxígeno disuelto. La remediación biotecnológica consiste en el uso de microorganismos que se aclimatan al contaminante y lo metabolizan transformándolo en un compuesto menos dañino. El mecanismo de degradación de los colorantes azo mediante el uso de bacterias se basa en el rompimiento reductivo del enlace azo por medio de la acción de enzimas llamadas azoreductasas bajo condiciones anaerobias. Sin embargo, los productos de reducción son necesariamente aminas aromáticas carcinogénicas que necesitan una degradación posterior.

Existen numerosos estudios que emplean especies de los géneros Bacillus, Pseudomonas, Aeromonas, Proteus y Micrococus que son efectivas en la degradación anaerobia de los colorantes azo (Saratale et al., 2011). En estas bacterias la actividad de las azoreductasas se lleva a cabo bajo condiciones anaerobias en un proceso bioquímico que se cree implica a la cadena de transporte de electrones donde el colorante azo actúa como un aceptor. El factor limitante de la velocidad de la decoloración es la permeación del colorante a través de la membrana por lo que incluso se ha sugerido que la reacción se da de forma extracelular. En contraste, sólo se han encontrado pocas bacterias con enzimas azoreductasas que funcionan bajo condiciones puramente aeróbicas. Ejemplo de ellas son la Xenophilus azovorans KF 46 y la Pigmentiphaga kullae K24 que pueden crecer aeróbicamente en carboxinaranja I y II (Saratale et al., 2011).

Para lograr la degradación completa del colorante sin detenerse en las aminas tóxicas, se han empleado consorcios microbianos capaces de atacar a la molécula de colorante en diferentes posiciones (no sólo rompiendo el enlace azo) causando, por ejemplo, hidroxilación y apertura de los anillos aromáticos en presencia de oxígeno. Así es común que durante el proceso de degradación completa de colorantes azo estén implicados tanto procesos reductivos como oxidativos.

También se han empleado enzimas oxidativas como las peroxidasas y lacasas ya que estas pueden romper las moléculas aromáticas sin que implique sólo el rompimiento del enlace azo. Sin embargo, la aplicación de hongos a la remoción de colorantes en aguas residuales tiene algunos inconvenientes como su largo ciclo de crecimiento lo que conlleva un tiempo de retención hidráulica mayor que cuando se usan bacterias. Las algas también son capaces de degradar colorantes azo a partir de una forma inducida de azoreductasas. Varias especies de Chlorella y Oscillatoria (Saratale et al., 2011) son capaces de degradar colorantes azo a las correspondientes aminas aromáticas y después metabolizar estas aminas a compuestos orgánicos simples o $\mathrm{CO}_{2}$.

\section{Otros usos para la celulosa}

Con el desarrollo de materiales nanoparticulados, recientemente se descubrió que las fibras de celulosa de tamaño nanométrico (nanocelulosa) tienen propiedades ópticas, mecánicas y de permeabilidad a los gases. Es decir, la celulosa es un material interesante para nuevas aplicaciones como soporte para dispositivos fotónicos, optoelectrónicos y biomédicos y en el almacenamiento de energía (Zhu et al., 2016).

Por otro lado, la preocupación por el uso del petróleo como fuente de energía debido a su calidad de recurso no renovable que genera graves problemas de contaminación como la emisión de $\mathrm{CO}_{2}$, causante del calentamiento global y óxidos de 
azufre que generan lluvia ácida, ha fomentado la exploración de alternativas más limpias entre las que se encuentra el uso de biocombustibles. Existen dos tipos de biocombustibles: el biodiesel que consiste en la trans-esterificación de grasas y aceites naturales y el bioetanol que es generado por fermentación microbiana de azucares. El bioetanol puede ser generado a partir de azucares comestibles como el almidón (llamado bioetanol de primera generación) o a partir de azucares no comestibles como la celulosa y la hemicelulosa (segunda generación). Brasil y Estados unidos son los principales productores mundiales de bioetanol de primera generación. Brasil obtiene bioetanol principalmente a partir de caña de azúcar y Estados Unidos a partir de maíz (Bellido, 2003). El bioetanol de primera generación es más fácil de producir debido a la variedad de microorganismos capaces de degradar almidones comparado con aquellos que despolimerizan celulosa. Sin embargo, ya que el bioetanol de segunda generación puede obtenerse a partir de desechos vegetales sin afectar la obtención de alimentos, puede hacer que el proceso sea atractivo. Se han explotado diversas fuentes de celulosa a partir de residuos agrícolas como bagazos, maderas duras y blandas e incluso papel y cartón de desecho. Una ventaja de usar papel es que estaría totalmente libre de lignina.

El primer paso de la obtención de bioetanol a partir de celulosa consiste en una hidrolisis enzimática para obtener glucosa a partir del polímero de celulosa. Las enzimas encargadas de romper los enlaces glucósidos $\beta-(1,4)$ se llaman celulasas y pertenecen a la familia de las hidrolasas glucosídicas, estas enzimas pueden ser producidas por hongos y bacterias como Saccharomyces cerevisiae (Wahono et al., 2015), Eucheuma cottonii (Sekar et al., 2015), Penicillium funiculosum (Nobuyuky et al., 2013), Trichoderma spp y Asperguillus ninger (Wertz et al., 2010). Las celulasas se han clasificado en endoglucanasas y exoglucanasas según el enlace glucosídico que rompan, ya sea en los extremos o intermedios en la estructura.

\section{English Summary}

\section{Microbiological methods to mitigate pollution problems generated by cellulose and paper industry}

\begin{abstract}
Despite the idea that paper is a sustainable material, the process for its production implies great consumption of water and electricity and the generation of many pollutants. The sustainability of this material rely on its recyclability, however, worldwide only $55 \%$ of total production is recycled. There are some biotechnology options that could help mitigate the pollution generated by this industry, for example, production of cellulose through bacteria, biopulping through enzymes and treatment of effluents by microorganisms. Although these options do not constitute a total solution to the problem, they could be part of an answer.
\end{abstract}

Keywords:

Biocellulose, biopulping, effluents, dyes, $2 \mathrm{G}$ bioethanol.

\section{Agradecimientos}

A la memoria del Ingeniero Químico Aurelio Chi González, quien diseñó y por muchos años impartió la materia de Celulosa y Papel en la licenciatura en Química. Con respeto y cariño.

\section{Referencias}

Ali, M., Sreekrishnan, T. R. (2001). Aquatic toxicity from pulp and paper mill effluents: a review Advances in Environmental Research, 5, 175 196

Arias-Orozco, P., Bastida-Gonzáles, F. G., Salgado-Manjarrez, E., ZárateSegura, P. B., Arias-Orozco, P., (2012) Produccón de enzimas lignoceluloliticas en fermentacion sumergida y sólida a partir de residuos sólidos orgánicos. Memorias XVIII Congreso Nacional de Ingeniería Bioquímica. Ixtapa-Zihuatanejo Guerrero, México., 28 al 30 de Marzo.

Bellido, C. (2003). Obtención de bioetanol 2g a partir de hidrolizados de paja de trigo. Fermentación conjunta de los penta y hexa carbohidratos con Pichia stipitis. Tesis Doctoral. Universidad de Valladolid. España.

Cañas, A., Camareno, S. (2010). Laccases and their natural mediators: Biotechnological tools for sustainable eco-friendly processes Biotechnology Advances. 28, 694-705.

Chávez- Pacheco, J. L., Martínez-Yee, S., Contreras-Zentella, M., Escamilla-Marván, E. (2004). Celulosa bacteriana en gluconacetobacter xylinum: biosíntesis y aplicaciones. Tip Revista Especializada en Ciencias Químico-Biológicas, 7, (1), 18-25

Chawla, P. R., Bajaj, I. B., Survase, S.A., Singhal, R.S. (2009). Microbial Cellulose: Fermentative Production and Applications. Food Technol. Biotechnol., 47, (2), 107-124

FAO (2015) Food and Agriculture Organization of the United Nations. Yearbook statistics. Forest Products. [pdf en línea] http://www.fao.org/3/a-i7304m.pdf

Garcia-Sanchez, M. E., Jimenez-Palomar, I., Gonzalez-Garcia, Y., Robledo-Ortiz, J. R. (2016). Bacterial Cellulose Produced by Gluconacetobacter xylinus Culture Using Complex Carbon Sources for Biomedical Applications. Materials Research Society, 36, (1) 2563-2564

Nobuyuky, R., Araújo, C., Melo, L. M., Pereira, N. (2013). Cellulase production by Penicillium funiculosum and its application in the hydrolysis of sugar cane bagasse for second generation ethanol production by fed batch operation. Journal of Biotechnology, 163, 38 44

Sánchez, E. R. (2006). Caracterización molecular de lacasas de Pleurotus eryngii: expresión heteróloga de estas enzimas y aplicaciones en la degradación de contaminantes aromáticos. Tesis doctoral. Universidad Complutense de Madrid Facultad de Ciencias Biológicas, Madrid, España.

Saratale, R. G., Saratale, G. D., Chang, J. S., Govindwar, S. P. (2011). Bacterial decolorization and degradation of azo dyes: A review. Journal of the Taiwan Institute of Chemical Engineers, 42, 138-157

Sekar, W., Makhmudun, D., Ari, H. (2015). The production of bioethanol fermentation substrate from Eucheuma Cottonii seaweed through hydrolysis by cellulose enzyme. Agriculture and Agricultural Science Procedia, 3, 200-205.

Singh, P., Thakur, I. S. (2006). Colour removal of anaerobically treated pulp and paper mill by microorganisms in two steps bioreactor. Bioresourse Technology, 97, 218-223

Singhal, A., Thakur, I. S. (2009). Decolourization and detoxification of pulp and paper mill effluent by Cryptococcus sp. Biochemical engineering journal, 46, 21-27

Vilaseca, M. M.(2001). Observación microscópica de fangos activados en los tratamientos de depuración biológica. Boletín INTEXTER Universidad Politécnica de Catalunya, 67-72

Wahono, S. K., Rosyida, V. T., Darsih, C., Pratiwi, D., Frediansyah, A., Hernawan. (2015). Optimization of Simultaneous Saccharification and Fermentation Incubation Time Using Cellulose Enzyme for 
Sugarcane Bagasse on The Second-Generation Bioethanol Production Technology. Energy Procedia, 65, 331-336

Wertz, J. L., Bédué, O., Mercier, J. P. (2010). Cellulose Science and Technology. $1^{\text {st }}$ Ed. EPFL Press Taylor and Francis Group. Boca Ratón FL.
Zhu, H., Luo, W., Ciesielski, P. N., Fang, Z., Zhu, J. Y., Gunnar, H., Himmel, M. E., Hu, L. (2016). Wood-Derived Materials for Green Electronics, Biological Devices, and Energy Applications. Chem. Rev., 116, 9305-9374 